\title{
EL EXPEDIENTE SIMANCAS, PARADIGMA DE UNA CONSPIRACIÓN DECIMONÓNICA
}

\author{
Diego Valor Bravo
}

\section{UNIVERSIDAD REY JUAN CARLOS}

\begin{abstract}
RESUMEN: Bajo este nombre se oculta una serie de documentos, confeccionados por Aviraneta como agente al servicio de la regente María Cristina, y que acabaron en manos del pretendiente al trono don Carlos en mayo de 1839 con el propósito de sembrar la discordia en su bando. De su análisis se obtenía la conclusión de que el jefe del ejército carlista, el general Maroto, estaba a las órdenes de esa logia.
\end{abstract}

PALABRAS CLAVE: Aviraneta; Espartero; Maroto; Carlismo; Masonería; Sociedad General de Jovellanos; conspiración.

\section{THE SIMANCAS FOLDER, A DECIMONONIC CONSPIRATION PARADIGM}

ABSTRACT: Hidden under this name are a series of documents written up by Aviraneta as agent at the service of Queen Regent Maria Cristina, and that, in May 1839 ended up in the hands of the pretender to the throne Don Carlos, with the purpose of sowing discord amongst his own bloc. From their analysis the conclusion was drawn that General Maroto, head of the Carlist army, was under the orders of the masonic lodge.

KEY WORDS: Aviraneta; Espartero; Maroto; Carlism; Masonry; General Society of Jovellanos; Conspiration.

Recibido: 09-06-2014/Aceptado: 27-11-2014 
La figura de Eugenio de Aviraneta ha pasado a la historia como verdadero paradigma de la conspiración, y así fue puesto de manifiesto por sus propios coetáneos ${ }^{1}$. Sobre su figura poco podemos aportar en este trabajo, aunque, en un intento de poner de manifiesto los perfiles de ella más interesantes para el mismo, este deseo se aclara mejor con la cita con la que la estudiosa del personaje, la catedrática García Rovira, comienza el capítulo que le dedicó, y que supone una buena aproximación a su vida, que cataloga como de paroxismo de la conspiración ${ }^{2}$. Este trabajo versa sobre un Aviraneta presa de un narcisismo desbordante, en paralelo a una vida de frustraciones, y comienza con la cita del novelista Pérez Galdós en su obra sobre él, en la que uno de sus personajes le califica de monstruoso talento, el más sutily agudo para la intriga... os digo que le dejéis solo en la febril inquietud de su conspirar instintivo, genial, por amor al arte, por ley de naturaleza. Tendremos ocasión de comprobar hasta qué punto se corresponde este apunte psicológico realmente con el propio Aviraneta; para ello tenemos ahora la ocasión de presentar uno de los puntos culminantes de su azarosa vida ${ }^{3}$.

\footnotetext{
1 Eugenio de Aviraneta e Ibargoyen, de origen vasco, nació en Madrid en noviembre de 1792. Sus ideales políticos se acrisolaron en la Guerra de Independencia cuando, tras pertenecer a la guerrilla del cura Merino, pasó a formar parte de la del Empecinado, más próximo a sus ideas progresistas. Tras formar parte de todo tipo de conspiraciones de distinto signo acabaría prestando sus servicios como agente en el fracaso del movimiento carlista. Sobre su biografía tenemos autores que reconocen la fascinación que les supuso, como Castillo Puche, J. L.: Memorias intimas de Aviraneta o manual del conspirador, Ed. Biblioteca Nueva, Madrid (1952). Fascinación que ya compartió el propio Pío Baroja siendo para él toda una fuente de inspiración. Biografía que quedaría plasmada en una colección de 22 títulos bajo el general de Memorias de un hombre de acción. La peripecia del Simancas está especialmente señalada en el volumen llamado Las figuras de cera. Más crítico con su figura fue Ortiz-Armengol, P: Aviraneta o la intriga, Ed. Espasa Calpe, Madrid (1994).

${ }^{2}$ García Rovira, A. M.: Eugenio de Aviraneta e Ibargoyen (1792-1872). El paroxismo de la conspiración. Publicado en Liberales, agitadores y conspiradores: biografías heterodoxas del siglo XIX, coord. por Isabel Burdiel Bueno, Manuel Pérez Ledesma, Ed. Espasa Calpe, Madrid (2000), pp. 127-154. La cita de Pérez Galdós está en Mendirábal, ed. Hernando, Madrid (1972), pp. 67 y 68. Sobre la psicología del personaje la autora la describe como la de un "conspirador cuya labor requiere en principio el secreto y la más exquisita discreción, pero que al mismo tiempo precisa perentoriamente el reconocimiento público al sacrificio de su vida. Un tipo de conspirador que airea a la más mínima oportunidad los secretos de las tramas societarias o las misiones de espionaje y de desestabilización del enemigo en las que ha participado. De ahí también que la megalomanía, la paranoia persecutoria, el narcisismo o la obsesión neurótica, provocados por la frustración de esas expectativas de reconocimiento, no sean tampoco patrimonio individual de don Eugenio". Ob. cit. p. 130.

${ }^{3}$ Por otra parte el propio Aviraneta no duda en considerarse asimismo un conspirador, en lo que demuestra el concepto beneficioso que él atribuía a esa "profesión". Así consta en su Contestación de Aviraneta a los autores de la vida política y militar del general Espartero, duque de la Victoria, Madrid (1864) donde dice de sí mismo y de su entonces jefe el ministro Pita: "Si Pita y yo fuimos conspiradores a favor de la libertad y del trono constitucional ¿qué español liberal dejó de ser conspirador en mayor o menor grado? ¿A quién debe España lo que es en el día y lo que dejó de ser, y lo que era entonces (1)? A los conspiradores, que antes de la muerte del rey don Fernando VII, conspiraron contra el absolutismo y a favor de la libertad. Díganlo los manes de los ilustres mártires de la libertad español; Porlier, Lacy, Vidal, Richard, Beltrán de Lis, Aviñó, y otros muchos que murieron en los patíbulos por "conspiradores"; y cuyos nombres se ostentan con gloria en las lápidas de mármol de las Cortes, para eterna memoria de las generaciones venideras. Ponga su mano en el pecho el historiador del duque de la Victoria, don José Segundo Florez, y diga francamente si fue ó no conspirador á favor de la libertad; si ha debido ó no la facultad de poder escribir libremente y el no volver á ser encerrado (2), al haber sido conspirador". De esta frase lapidaria y encendida contra el historiador oficial de su enemigo Espartero podemos destacar para intentar conocer al personaje las dos notas que añadió y que hemos señalado. La (1) es una definición del término conspirar, con una idea que quiso remarcar: "unirse algunos contra su superior ó soberano". Más polémica es la nota (2) que supone una crítica mordaz contra Segundo Florez al indicar con cierta mala idea que según sus "noticias, el señor Florez, es un fraile exclaustrado". Ob. cit. pp. 4-5.
} 
Me refiero al conocido como Expediente Simancas, documento que se encuentra entre los fondos del Archivo General del Palacio Real de Madrid, y que aparece dentro de la antigua Colección Fáctica de la que fuera regente, la reina María Cristina, y que en la actualidad se encuentra en el mencionado archivo, exactamente en la Sección Reinados Fernando VII ${ }^{4}$. Este documento es el que tenemos el placer de presentar y poner a disposición de los investigadores, y se enmarca dentro de las acciones de Aviraneta llamadas a provocar la defección en el bando carlista ${ }^{5}$. Esta situación ya podemos imaginar que era la típica de las actividades de nuestro personaje, teniendo en cuenta su trayectoria personal. De su biografía tenemos que destacar, para centrar algo el asunto, que Aviraneta, tras varias andanzas y participaciones conspiracionistas de todo tipo tanto en América como en España, se acabó ganando la antipatía de los progresistas dirigidos por Mendizábal. En este contexto de enfrentamiento con los progresistas y corriendo el año 1837, se puso al servicio de la regente María Cristina, a la que el mismo designaba con el cariñoso apelativo de ama, y del poderoso ministro Pita Pizarro. Servicio que acabaría con su viaje a Bayona en enero de 1839, circunstancia que permite entender las razones de la aparición del Simancas entre los papeles personales de la regente ${ }^{6}$.

Durante esa estancia como agente de la reina, entre otras muchas acciones Aviraneta ideó un plan sorprendente para descomponer el bando carlista, que por otra parte estaba ya siendo presa de rivalidades. La cuestión era hacer llegar al entorno del propio don Carlos unos documentos, que el autor luego designaría bajo el epígrafe de Expediente Simancas, cuyo examen pormenorizado implicaba el reconocimiento de que el general Maroto era el líder de una supuesta facción masónica introducida en el ejército carlista.

\footnotetext{
${ }^{4}$ El documento aparece exactamente en dos referencias, la primera es AGP Sección Reinados Fernando VII caja $28 / 29 \mathrm{n}^{\circ} 2$, siendo una copia del reglamento y del cuadro sinóptico originales. La segunda referencia y más importante es la de AGP Sección Reinados Fernando VII caja 33 n 2, correspondiendo al Expediente Simancas original. Lo curioso es que este expediente aparece en esa caja 33 donde se encuentran todas las cartas dirigidas por y a este personaje, con lo que llama la atención que este documento haya pasado hasta ahora completamente inadvertido.

${ }^{5}$ Aviraneta realmente fue el arquetipo del espía de la época como así indica la obra de Simón Palmer, $\mathrm{M}^{\mathrm{a}}$ del C.: El espionaje liberal en la última etapa de la Primera Guerra Carlista, nuevas cartas de Avinareta y de F. de Gamboa. Publicado en Cuadernos de Historia, tomo IV. Madrid, Instituto Jerónimo Zurita, 1973, p. 289-380.

${ }^{6}$ Así aparece en una curiosa carta que él le remitió. AGP Sección Reinados Fernando VII caja 15 exp. 1. Por su parte la regente hace unos curiosos comentarios de admiración sobre su figura en una carta que remite al marqués de Miraflores y que está en la referencia AGP Sección Reinados Fernando VII caja 15 exp. 6.
} 
El éxito más sonado de esta conspiración fue el fusilamiento en Estella, siguiendo las órdenes de Maroto, de otros cuatro generales carlistas ${ }^{7}$. El nombre de la logia, Sociedad General de Jovellanos acabaría trascendiendo y cobrando vida propia, hasta el punto de que su efectiva existencia ha sido muy discutida por la historiografía. Todavía hoy en día no podemos negar la exactitud de la entidad fáctica de la tal Sociedad, como veremos más adelante, aunque todo apunta a que nunca llegó a ser una estricta y regular organización masónica, quedando reducida su naturaleza a un simple nombre o a una consigna. Precisamente en su Memoria dirigida al Gobierno Español en 1841 el autor habla de este documento en estos términos:

A Maroto y a aquellos gefes que pertenecían a su cuerda, los representaba como corifeos de dicha sociedad, siendo el primero el presidente del triángulo mayor del Norte de España, pues que se suponían muchos triángulos organizados en los batallones disidentes y entre los principales habitantes del país. Compuse un cuadro sinóptico, una esfera para descifrar los signos y geroglíficos. Y la correspondencia civil, escrita en papel de fábrica español, con membretes impresos y adornada con dos magníficos sellos; en fin, con todos los atributos necesarios para no dejar la menor duda acerca de la existencia cierta de tal asociación ${ }^{8}$.

Tomando esta definición podemos afirmar que el documento que presentamos es el original, lo que nos va a permitir tener una magnífica oportunidad de saber algo acerca de lo que podríamos calificar como arquetipo de una conspiración. Para el entendimiento de ello debemos empezar analizando el especial valor que se le daba en esa época a esas operaciones realizadas en la sombra, al margen de los cauces legítimos. Esta circunstancia se daba en un momento en el que los medios de participación política todavía eran muy reducidos para un estado cuyas instituciones, que podían haber dado cauce a ella, estaban todavía en formación, con lo que la actividad conspirativa tenía cierto sentido, cosa por otra parte, reconocida por los afectados. Esta forma de participación, al margen de su naturaleza, era reconocida como algo que formaba parte de la actividad social, con lo que

\footnotetext{
${ }^{7}$ La aventura de Aviraneta llegó a tener tanta estima para sus coetáneos que el gran historiador de las Guerras Carlistas, Antonio Pirala, a la sazón amigo personal de Aviraneta, llegó a considerarla digna de especial mención dedicándole en exclusiva un capítulo. Pirala, A: Historia de la guerra civil y de los partidos liberal y carlista, Madrid (1868-1869) Imprenta señores P. Mellado, vol. V pp. 428-433. Entre los comentarios del historiador está el final, que creo que describe la opinión general que se tenía del suceso en sus cercanos años: "Pocos habrían ejecutado la difícil comisión de Aviraneta con más acierto y desinterés; pues en vez de lucrarse en lo más mínimo, fue exiguo el gasto que hizo, y devolvió el dinero que le sobró, aunque se le cedía. El desinterés y la honradez han sido patrimonio siempre de Aviraneta, uno de los hombres que más servicios han prestado a la causa liberal y a España. su notable historia merece ser conocida”. Ob. cit. p. 433 n. 1.

${ }^{8}$ Esta referencia y otras las he sacado de la edición del título Memoria dirigida al gobierno español sobre los planes y operaciones puestos en ejecución, para aniquilar la rebelión en las provincias del norte de España, Imprenta de don Narciso Sánchiz, Madrid (1844).
} 
un breve análisis de un ejemplo de esa participación, como fue el Simancas, nos puede permitir saber algo acerca de las ideas más o menos convencionales que estaban en circulación en la España del momento. Claro, que en todo momento tendremos que tener en cuenta que esos convencionalismos políticos siempre pasaron por el tamiz de la particular psicología de un Aviraneta cuyos perfiles personales, como tendremos ocasión de examinar, se van a ver reflejados en el texto. Con este propósito, si tenemos en cuenta los objetivos del autor del complot, el conocer de primera mano el instrumento del que se valió para hacer circular ciertos hechos de forma interesada, esto es el citado expediente, nos facilita la compresión del constructo ideológico que se transmite en el texto, al menos su valor convencional, y también nos aproxima a las ideas más recurrentes de su autor. Con esto tenemos con el Simancas original un instrumento muy singular a nuestro alcance para comprender los mecanismos políticos e ideológicos que estaban en circulación en una España en una rápida transformación hacia un futuro constitucional, cuyo definitivo triunfo final se presentaba todavía como incierto.

Uno de estos convencionalismos políticos, que otorga esa especial consideración al documento, es, sobre todo, el papel que jugaban en aquellos tiempos las conocidas sociedades secretas masónicas?.

La valoración de la masonería strictu sensu excede las pretensiones de este trabajo, que sólo intenta hacer una breve aproximación al valor que se concedía a esas sociedades secretas, siempre tomando en consideración su operatividad y funcionamiento exterior y en ningún caso su dinámica cultual interna. Con todo, sí podemos afirmar que en aquellos años, como tendremos ocasión de ir comprobando, el papel que jugaba la masonería era

\footnotetext{
${ }^{9}$ La mejor exposición de esas ideas generales las realiza el propio Aviraneta, supuesto masón, cuando escribe la carta que los delatores hacen llegar a don Carlos junto con el Expediente Simancas: "En mi primera nota de hace dos meses espliqué la clase de papeles que había dejado en su posada el agente de una sociedad secreta que procedente de Madrid vivía en una quinta, correspondiente con Maroto y sus cómplices, y que hace dos meses se trasladó al ejército de Espartero, dejando en su cuarto el cofre y en él los papeles pertenecientes a la sociedad. La familia legitimista en cuyo poder dejó el baúl y los papeles el comisionado de la sociedad secreta y que me hizo la confianza de consultarme y entregármelos para su ecsamen, quiso así como yo hacer un señalado servicio a S. M. el rey don Carlos. se buscó persona segura que marchase al campo del rey con la citada nota a fin de que se proporcionase medio de que llegasen dichos papeles al alto conocimiento de S. M., y de este modo evitase los efectos de una pérfida traición... Con la simple lectura de esta larga y secreta correspondencia, verán S. M. y su consejo el origen de los horrendos asesinatos perpetrados por Maroto en Estella en las personas de los cuatro generales más valientes y fieles que tenían el Trono y la Religión; aquella pérfida trama urdida por los tenebrosos manejos de los infames fracmasones que han conseguido minar una parte del ejército real y el campo de la lealtad. S. M. se penetrará así mismo de que los sectarios de esa secta impía, han sido los verdaderos autores de la proscripción que sufren el virtuoso y leal obispo de León y sus compañeros de infortunio... Esa ha sido la obra diabólica de los revolucionarios. Mi ignorancia en esta clase de cosas no me ha permitido descifrar los muchos geroglíficos que tiene la correspondencia y el cuadro sinóptico, ni he querido fiarme de personas que acaso hubieran podido traducirlo, pero el gobierno de S. M. encontrará tal vez en ese campo algún inteligente que por medio de la esfera de la luz que va en la caja de cartón, descifre los misterios y secretos de la mayor importancia. La traición es evidente, y el riesgo de S. M. muy inminente. Bayona 30 de julio de 1839”. Ibíd. pp. 141-143.
} 
bastante grande, estando muy desarrollada su estructura, hasta el punto de que los coetáneos próximos y allegados al mismísimo don Carlos no dudaron nunca, ni por asomo, de la masonería estaba jugando sus cartas en la guerra civil. La presencia de la Masonería era tan sentida y tenida en cuenta que no se dudaba de su participación, lo que demuestra que al menos se prestara cierta atención al Simancas. Esta idea fundamental parece complementar la idea general de los concienzudos estudios de Ferrer Benimeli y su equipo, para quienes la existencia de una masonería organizada anterior a 1868 se reduce a breves manifestaciones durante la Guerra de Independencia y el Trienio Liberal ${ }^{10}$.

Sin querer avanzar más en el sentido de lo expuesto, y centrándonos en el documento que examinamos, lo que llama la atención tras una primera lectura es que, las ideas que podemos denominar como "populares" en torno a la masonería, ya estaban en circulación en esas fechas. Este convencionalismo ideológico llegaría hasta nuestras fechas en torno a esas sociedades secretas a las que, en general, la opinión pública concedía, tal y como se hace hoy en día, unas posibilidades de acción muy fuera de lo común. La idea de esa instrumentalización, para nuestro caso, sería denunciada por la propia historiografía especializada en la masonería, que en general consideraba la obra de Aviraneta como un verdadero despropósito desde el punto de vista formal y de la forma ordinaria de funcionamiento de esas sociedades secretas. Ello también sirvió de feroz crítica atribuyéndole, en general, un desmedido afán de protagonismo ${ }^{11}$.

\footnotetext{
10 'Pero dado el estado actual de elaboración de las correspondientes historias masónicas regionales y, sobre todo, las dificultades de conocer exactamente la situación puntual y concreta de las logias en cada momento, ha hecho que el presente trabajo se oriente -como posible ayuda metodológica- a reseñar la implantación de las logias en España más que en fechas concretas, en periodos definidos por la propia documentación que nos ha sido conservada. Periodos que vienen delimitados por una fecha clave: 1868, que sirve de pauta y división. En este sentido, entre 1800 y 1868 he establecido dos grandes bloques. El primero, el llamado de la masonería bonapartista, hasta 1814, y del que existe suficiente -aunque no abundante- documentación para que podamos hacer una primera aproximación. Y el segundo, que va desde 1814 hasta 1868; es decir, los reinados de Fernando VII e Isabel II, y que coincide con un largo periodo de represión, persecución e ilegalidad de la masonería, todavía no demasiado conocido, sobre todo por la escasez de la documentación que ha llegado hasta nosotros". Ferrer Benimeli, J. A.: Implantación de logias y distribución geográfico-histórica de la masonería española” p. 58. Publicado en La masonería en la España del siglo XIX, Actas del Simposium de Metodología Aplicada a la Historia de la Masonería Española, 2 (1985) Salamanca pp. 57-216.

${ }_{11}$ Así fue señalado el extraño carácter de la intervención de Aviraneta como muy fuera de lo corriente, y con esta idea quedaría para el futuro, atribuyéndolo en general más a su extrovertido carácter que al de un verdadero profesional del asunto del espionaje. De la Fuente, V:: Historia de las sociedades secretas antiguas y modernas en España y especialmente de la Franomasonería Tomo II p. 81-86. Imprenta a cargo de D.R.P. Infante, Madrid (1874-1882): 'Tibreme Dios de calificar de tal á D. Eugenio Aviraneia, que no me gusta usar de semejantes calificaciones; pero es lo cierto que los progresistas le han negado toda importancia, (que los moderados la rebajan mucho, y los carlistas, admirados de ver cuán sobornable era su gente, cuan tontos sus jefes, y cuanto pícaro sin Dios ni religión había entre los defensores del Aliar y el Trono, tampoco se han mostrado dispuestos á creer las revelaciones de Aviraneta". Ob. cit. p. 82. Otras manifestaciones sobre Aviraneta aparecen en la p. 24: "Concluiremos estas observaciones admirando la modestia del director presunto Aviraneta, que trabajaba en su oficio de conspirador, sin dinero y sin caballo, y solo por amor del arte. Preguntando yo á un ministro moderado, que tuvo algunas relaciones con Aviraneta para los sucesos de Vergara, acerca de la importancia de sus gestiones y de la exactitud de sus revelaciones, me contestó: Aviraneta en todas sus relaciones exagera la importancia de su persona y de sus cosas; calla lo que debía decir y dice lo que debía callar. Y en efecto, sin negarle el mérito de gran conspirador, hay que tener en cuenta que era instrumento y pie más que cabeza; pero, en su presunción, cambiaba algunas veces el papel de testaferro por el de director".
} 
Exceso de protagonismo que, por otra parte, y en un sentido muy parecido al de la situación del Simancas, ya había tenido Aviraneta ocasión de demostrar tal y como sucedió con la creación en 1833 de otra sociedad secreta masónica a la que llamó Confederación General de los Guardadores de la Inocencia o Isabelinos más conocida como La Isabelina. Bajo esta Sociedad quedarían englobados conocidos liberales como el general Palafox, Espronceda u Olavarría, junto a líderes masónicos de primer orden como el mítico Juan Van Halen; u otros como Romero Alpuente, Calvo y Mateo, Calvo de Rozas y Flórez Estrada. Esta Sociedad habría estado destinada a conspirar contra el gobierno de Cea Bermúdez, y el posterior del conde de Toreno, y Aviraneta no duda en concederle el protagonismo de haber sido la que dirigiría la revolución de 1835 bajo su mando directo personal, en lo que parece otra muestra más de una personalidad que parece rayar en un desproporcionado narcisismo ${ }^{12}$.

Y es que hacer una valoración de la acción de Aviraneta, y del resultado de la misma, ha dado lugar a interpretaciones de mucho tipo. Desde las ya indicadas, concediéndole escaso valor a su acción, hasta otras que llegan al extremo de situar la misma dentro de una conspiración demasiado exuberante ${ }^{13}$. El hecho de situar el Simancas dentro de una hipotética conspiración de otra hipotética sociedad masónica no ayuda demasiado a comprender el valor de la acción de Aviraneta.

\footnotetext{
12 Sobre esta sociedad Busquets, J.: Las sociedades secretas militares en la primera transición española: La Isabelina (1833-1836). Publicado en Masonería, revolución y reacción, vol. 1, coord. Ferrer Benimeli, Madrid (1990) pp. 7990. Más datos en García Rovira, M. A., ob. cit. 2 pp. 139-144.

${ }^{13}$ La visión más positiva de Aviraneta, al margen del citado Pirala, la tenemos en Lafuente, M.: Historia General de España. Desde los tiempos primitivos hasta la muerte de Fernando VII. Continuada desde dicha época hasta nuestros días por Juan Valera, con la colaboración de Andrés Borrego y Antonio Pilara. Barcelona, Ed. Montaner y Simón (18771882) vol. VI pp. 292-293: “Consecuencia de esta doble situación de descrédito en Aviraneta y de reparo en abandonarlo por parte de los que lo empleaban, resultó que al ser enviado por la Reina y por Pita para entablar sus trabajos de zapa contra el carlismo (esta es una buena definición de la misión de Aviraneta), sujetaron a su hombre de confianza a una dependencia y fiscalización del cónsul de Bayona, que hasta cierto punto coartaba la libertad de acción de Aviraneta y perjudicaba al éxito de sus trabajos. Espartero y sus generales, igualmente prevenidos contra el agente secreto, desautorizaban y estorbaban de mil maneras la espontaneidad de sus movimientos; circunstancias todas estas que dan mayor valor a los servicios de Aviraneta, los que, como se verá, no fueron estériles y antes al contrario contribuyeron a la venturosa catástrofe que lanzó a don Carlos del territorio español, sin que deba dejarse de tener en cuenta que los amigos de Aviraneta le atribuyen en el éxito de los trabajos que condujeron al tratado de Vergara, una participación que fue en gran parte obra y efecto de hechos ajenos a la inmediata y directa acción del agente secreto".
} 
Estas especulaciones sobre el papel general de la masonería dentro del carlismo, llegarían a tal extremo que autores modernos como el marqués de Valdelomar, Jorge Plantada y Aznar, no dudaran en calificar el carlismo en su totalidad como fruto de una gigantesca conspiración masónica dirigida a dividir a los adictos al Trono y el Altar ${ }^{14}$.

Otro asunto de especial importancia en el documento es el de las relaciones de la masonería con la corona en un ambiente general de supuesta concordia mutua y entendimiento, habida cuenta de que el texto transmite la idea de que las actividades de los jovellanistas eran en cierta medida conocidas por la monarquía. Esta colaboración podría parecer estar fuera de la realidad, aunque tenemos que tener en cuenta que las relaciones entre esas dos instituciones, afectadas y participantes, como eran ambas, en el ámbito de la soberanía política, en algún momento tenían que encontrarse.

Precisamente sobre el tema de ese posible entendimiento entre masonería y corona tenemos un documento muy significativo en el Archivo General de Palacio, que puede servirnos además para conocer el estado general de la masonería en esos años. Se trata de un cuidadoso y concienzudo informe redactado por la policía secreta de Fernando VII, que aparece junto con otros muchos redactados por los agentes fernandinos ${ }^{15}$. Entre ellos destacan los de la conspiración de Juan Van Halen, u otras importantes referencias a otras de ellas incluyendo abultados listados de miembros, como en los casos de las

\footnotetext{
${ }^{14}$ En su obra Carlismo y Masonería: tácticas alucinantes, Ed. Prensa Española, Madrid (1972) pp. 139-140 afirma que: "Históricamente, el partido carlista nace del anhelo de la Francmasonería de crear un partido de oposición a la Corona en 1823, con el fin de restaurar el caído sistema liberal. tal anhelo figura en los extensos y detallados planes subversivos de la secta de los años 1823 y 1824, que puestos por obra, dan origen al partido agraviado-carlista de oposición a la Corona entre 1825 y 1828, que con la Guerra dels Malcontents, pretendía destronar a Fernando VII a favor de su hermano Carlos V, motivo por el cual se llamó "carlista" a partir de 1828; aunque en realidad aquella guerra era una cuña sectaria para repetir la revolución de 1820 restaurando nuevamente el sistema liberal". Objetivo que se consiguió mediante el empleo por la masonería de lo que este autor denominaba técnicas alucinantes, y dentro de ellas la que llama indirecta o masónica que "consiste en dar realidad efectiva a un entramado de supercherías y verdades palmarias, con ánimo perverso de obtener una aparente evidencia de verdad de tal magnitud que mueve al individuo, personal o colectivamente, en determinada dirección preconcebida por el agente, partiendo del conocimiento psicológico del sujeto". Técnica que se opone a la que este autor llama directa o comunista constituida formalmente por el empleo de ¡drogas psicodélicas! Ob. cit. pp. 37-38. La misma idea está expuesta en Liberalismo y Masonería: fraudes intelectuales, Ed. Prensa Española, Madrid (1973) p. 23: “cuando allá por el año de 1834 la Masonería aguzaba el ingenio para colarnos por tercera vez el sistema liberal, constitucional y democrático, es decir la utopía del gobierno del pueblo". O en Fernando VII y la Masonería: españoles, unión y alerta, Ed. Prensa Española, Madrid (1973) pp. 202-204 nota 43: "el carlismo fue el más noble instrumento del que se sirvió la Masonería en el siglo XIX para hostilizar y combatir a la Institución Monárquica... la misión asignada al carlismo desde su origen, mantenida y estimulada convenientemente, impidiendo cualquiera de los arreglos que se intentaron para terminar con la división y enfrentamiento de las dos ramas, se consumó plenamente en detrimento de las dos, y, como consecuencia, en detrimento de España... La Masonería es maestra en saber explotar los sentimientos humanos, desde el más sublime hasta el más bajo. Quien no comprenda esto nunca sabrá lo que es la Masonería".

15 AGP Papeles Reservados Fernando VII T. 67 pp. 208-214.
} 
conspiraciones de Barcelona y del Puerto de Santa María ${ }^{16}$. En el que nos interesa destacar, que se incluye en los folios 208 a 214, y que desgraciadamente no tiene firma ni fecha, aunque por otros de dicho libro podemos suponer redactado en torno a 1825-1827, se cita una breve historia de la masonería española. Según este documento informa, tras la entrada de las tropas napoleónicas, la entonces emergente masonería española resultó dividida en dos bandos irreconciliables. Uno de ellos refugiado en Cádiz y promotor de la resistencia al invasor y de la constitución gaditana, tras la guerra y el fin de la Constitución continuará con su dirección reorganizada en Granada en 1814, de donde pasaría en un momento dado a Madrid. Instalada esa masonería en la corte, recibiría el nombre general de moderna o el más popular de gorros colorados, fundando un Gran Oriente propio, y siendo el órgano de difusión de las ideas del bando constitucionalista. Esta facción masónica luego quedaría englobada dentro del movimiento de los comuneros y carbonarios en una, por otra parte, situación de división interna bastante confusa. Mientras tanto la masonería afrancesada, cuya dirección permaneció en Madrid bajo el amparo y protección de José I, continuaría su existencia tras la guerra en la capital bajo la denominación general de antigua. La unión de esos dos bandos resultaría imposible, siendo la citada masonería moderna más "exaltada" y próxima a un ideal republicano, mientras la antigua defendía opciones políticas más moderadas. La situación de división continuaría durante los siguientes años, con un mayor enconamiento en sus posiciones ideológicas que se exacerbarían con el fin del Trienio Liberal, llegando en esa dinámica al menos hasta el momento del que nos cabe hablar.

Lo curioso e interesante de este documento para nuestros intentos de analizar las relaciones entre la masonería y la corona que, recordemos fue redactado por la implacable policía de Fernando VII, es que en el mismo se pone en gran valor a esa masonería antigua moderada, cuyo estímulo se justificaba como forma de servir de contrapeso a los arrebatos de la exaltación. Este comentario viene a significar que, incluso dentro de los círculos más reaccionarios, se veía a parte de la masonería como eficaz instrumento político. Tal idea llevaría a la determinación de ofrecer su dirección al mismísimo infante don Carlos, el mismo que luego encabezaría el bando de su nombre, bajo los mismos principios que habían determinado que, en otras monarquías europeas, algunos de sus miembros ostentasen ese singular título. Esta era una manera de que la masonería moderada pudiera combatir las ideas revolucionarias, que en ese momento estaban siendo promovidas por los carbonarios y comuneros, herederas ambas facciones de la masonería gaditana. No

\footnotetext{
16 Un análisis detallado de ese documento y de las conspiraciones masónicas investigadas lo tenemos en el artículo de De Diego García, E.: Aproximación al estudio de los posibles masones en 1823. Publicado en La masonería en España en el siglo XIX, vol. 21987 pp. 451-466. Coord. Ferrer Benimeli, J. A. Actas del Simposium de Metodología Aplicada a la Historia de la Masonería Española, Salamanca (1985).
} 
conocemos el resultado de esa determinación ni podemos saber, por el momento, a salvo de la posible aparición de alguna referencia documental en el futuro, si el citado don Carlos fue Gran Maestre del antiguo Gran Oriente, lo que se comprende teniendo en cuenta el carácter secreto interno de esas asociaciones. Pero sí sabemos, o al menos es reconocido por toda la historiografía, que su hermano el infante don Francisco Pascual sí que ostentaría esa suprema dirección al menos desde la muerte de su hermano Fernando VII. En cualquier caso este hecho viene a servirnos para comprender las relaciones de cierta parte de la masonería, tenida por más próxima y moderada, con el trono español ${ }^{17}$.

En cuanto a la caracterización general de la masonería, este curioso informe acaba con el explícito comentario de que las asociaciones secretas son una enfermedad del siglo. Comentario que se comprende, teniendo en cuenta que su difusión por la España de la época era espectacular, y con el que se remarcaba que el gobierno debía contar con ellas estableciendo cauces de colaboración como forma de conseguir el establecimiento del orden público y la consolidación de las instituciones. A tanto parecía llegar entonces la capacidad de estas singulares hermandades. En todo caso este comentario, junto con lo ya citado arriba, hay que contextualizarlo debidamente, para intentar evitar caer en tesis excesivamente conspiracionistas. $\mathrm{Y}$ es que hay que tener siempre en cuenta para intentar evaluar la capacidad de acción de esas sociedades los escasos ámbitos y cauces de expresión política de la época. Pensemos que, en una sociedad como la de entonces, muy atrasada y con escasos medios de comunicación pública, el desarrollo de la actividad política, tanto práctica como ideológica, en muchos casos, tenía que hacerse mediante el asociacionismo y las reuniones privadas en clubes, cafés, tertulias y asociaciones de todo tipo. La pertenencia a la masonería, era por lo tanto, la única forma de poder acceder a una vía abierta de manifestación de las ideas políticas, lo que, sin duda, contribuyó a su enorme éxito entre las elites ilustradas.

Por último debemos poner de relieve en cuanto al tenor del Simancas, y con esto empezamos a analizar sus elementos formales, que su objetivo era hacer evidente su vinculación con una hermandad masónica a través de la descripción de los tópicos generales sobre la supuesta forma de funcionamiento de estas sociedades. Aviraneta hacía uso de la imagen convencional que tenía la sociedad del momento sobre la masonería, con lo que necesariamente aparecen en los documentos todos los estereotipos acerca de esta particular institución. En concreto me refiero al uso de la supuesta simbología que

${ }^{17}$ Sobre la pertenencia del infante don Francisco de Paula a la masonería tenemos la obra de Moral Roncal, A. M.: El Infante don Francisco de Paula Borbón: masonería y liberalismo a la sombra del trono. Publicado en Investigaciones históricas: Época moderna y contemporánea no 20 (2000) pp. 149-168. 
necesariamente tendría que aparecer en cualquiera de sus documentos, acudiendo al lugar común entonces extendido que decía que esas sociedades usaban de unos símbolos e iconos muy determinados.

Podemos empezar el análisis por el cuadro sinóptico, que resulta un esquema bastante rudimentario de la supuesta sociedad, siguiendo una distribución piramidal desde la Dirección General hasta el último de sus miembros en la base. Esta estructura se iba ampliando, estando siempre dos personas bajo la dirección de un superior, de forma que, siguiendo un dibujo de triángulos seguramente confeccionado dado el supuesto valor de este símbolo geométrico para los masones, se llegaba hasta la base de la organización. El esquema tomaba la forma de un abanico donde aparecen los supuestos integrantes señalados con un número desde el 1 hasta el 127, número que sería el de los miembros de la sociedad. En los bordes de este abanico aparecen los términos civiles y militares, y bajo estos epígrafes los nombres de los miembros correspondientes a cada colectivo.

En cada uno de los documentos del expediente aparecen, siguiendo la idea comentada de que respondiera el Simancas al tópico general sobre la masonería, unos curiosos sellos estampados y lacrados, con los que se intentaba dotar al documento de cierto carácter fáctico real. El símbolo de estos sellos, que es el de la Sociedad, es un triángulo equilátero sobre cuyo vértice superior se coloca una gran corona real. En el interior del triángulo aparece la imagen rotunda de dos cetros cruzados, símbolo de la buscada unión de los dos bandos en contienda, pues tal era el objetivo último que esa Sociedad había definido en su reglamento interno. Junto a este sello, la firma del secretario de la Sociedad, y en el centro del abanico una serie de símbolos geométricos y números formando una supuesta clave. Con estas omnipresentes formalidades se cubría la apariencia formal de este documento y a través de ellas podemos saber que las ideas acerca de la simbología usada por la masonería ya estaban en circulación.

Siguiendo con esta última idea citada, el hacer el Simancas y su procedencia masónica totalmente creíble, pasamos a hablar de la naturaleza formal del tenor literal del documento, donde tenemos que destacar dos ideas fundamentales atendiendo al aspecto puramente material del mismo. Lo primero es que todos los textos aparecen redactados con la misma letra, la misma tinta, y la misma pluma o estilete caligráfico, lo que debería haber despertado algunas sospechas. Además, un simple vistazo al documento en conjunto lleva a la conclusión de que parece redactado de un tirón, cosa que tampoco parece haber suscitado dudas sobre su legitimidad. A esta ausencia de crítica pueden haber ayudado las rivalidades en el bando carlista, en cuyo seno algunos miembros estaban entonces 
intentando por todos los medios acabar con la figura de Maroto, para lo que no dudarían seguramente en hacer uso de cualquier instrumento que llegara a su alcance.

También podemos hablar del estilo de las cartas contenidas en el expediente que están redactadas en un lenguaje muy directo cuando no bastante grosero ${ }^{18}$. El ingreso de los miembros según el expediente parece hacerse fuera del ritual masónico ordinario, pues se hace efectivo de forma directa, sin la necesaria iniciación que es requisito indispensable para ingresar en la masonería, y todo ello excusable con la expedición de un simple diploma acreditativo $^{19}$. Solamente estos cuestiones deberían haber hecho sospechar de su veracidad, si tenemos en cuenta que el lenguaje usado por la masonería era profundamente filosófico y lejos de exposiciones tan gruesas como las que se manifiestan en las $\operatorname{cartas}^{20}$. En cualquier caso, el tenor con el que están redactadas nos dice mucho acerca de la leyenda popular que ya circulaba entonces en torno a las sociedades secretas. El intento de identificación de la Sociedad con esta leyenda podría ejemplificarse con el uso en todos los documentos de la expresión de salud, moderación y esperanza, que parecía ser el saludo general de la logia y que se entiende como una forma explícita de situarla dentro de la opción política del moderantismo. Se podría colegir de ello que era un truco para adaptar el complot a la imagen popular de las actividades masónicas y situar la Sociedad en torno a ese partido. A esto se añade la profusión, demasiado directa y hasta un tanto naïf, de una simbología que se habría de interpretarse como masónica por cualquiera que la viese. Símbolos geométricos y claves numéricas que se podían interpretar usando de una supuesta esfera de la luz, artilugio que no se describe y que Aviraneta también hizo llegar a don Carlos. Tal artefacto permitía poder interpretar esas claves numéricas y simbólicas que aparecen en el texto, y que sin duda proporcionaban más nombres de supuestos traidores.

\footnotetext{
18 De un análisis muy rápido podemos extraer suficientes conclusiones sobre el extraño carácter formal del Simancas, al menos del uso del lenguaje que se realiza en el documento. Por ejemplo en el Simancas se hace referencia a un cuadro sinóptico, cuando el término corriente en el argot masónico es cuadro lógico, que es como se denomina al conjunto de hermanos de una logia. El jefe de la sociedad era un Director General, término muy lejano al corriente dentro de las logias de Gran Maestro. O el llamar a los miembros de la sociedad amigos, en vez del común de hermanos. Toda la terminología masónica, de interés para comparar el texto, la tenemos en Álvarez Lázaro, P. F.: La masonería, escuela de formación del ciudadano, Ed. Universidad Pontificia Comillas, Colección del Instituto de Investigación sobre Liberalismo, Krausismo y Masonería, 13 (2005) Madrid pp. 1726.

${ }^{19} \mathrm{El}$ ingreso en la masonería se realizaba conforme a un complejo ritual, que se realizaba necesariamente en el Templo de cada logia. En este sentido es inconcebible un procedimiento como el descrito en las cartas del Simancas. Para estudiar el ritual de ingreso tenemos un detallado estudio en la obra citada en la nota anterior pp. 189-284.

20 "Pero últimamente el Sr. Pirala ha publicado hasta el reglamento de los Jovellanistas, documento vulgar, calcado sobre los de sociedades análogas, como la del triángulo y otras. El preámbulo, que cree inédito, valiera mas no haberlo publicado, pues está escrito en tonto y se conoce la mano de un falsario adocenado. Y en verdad que á los moderados y á los jesuitas se les han imputado graves crímenes; pero nadie los ha llamado tontos, y el documento presentado como de los Jovellanistas es tal, que nadie lo creerá escrito por los jefes del partido moderado, que, en general, eran excelentes literatos, y entre los cuales el mismo supone á Martínez de la Rosa y a los hombres más importantes de la misma comunión.” Ob. cit. 11 p. 80.
} 
Desgraciadamente, al no contar con este aparato, no nos cabe poder determinar los nombres a los que harían referencia las claves.

Toda esta puesta en escena parece contraponerse con el propio Aviraneta al que siempre se ha vinculado a la masonería regular. De ser esto cierto debería conocer con exactitud su lenguaje y métodos, cosa que el texto del Simancas parece desmentir. Claro que también podemos pensar que quiso presentar unos papeles que se adecuasen a la imagen convencional que se tenía sobre la masonería, intentando que se ajustasen tanto a esa idea popular que el documento final resultase, a ojos de un examinador juicioso, un verdadero despropósito. Este es otro de los aparentes misterios de este singular documento cuya solución parece estar en la peculiar mente de un Aviraneta consagrado a la conspiración, y poco preocupado del rigor y la verdad.

Insistiendo en los elementos formales, dentro del texto del Simancas aparecen engarzadas una serie de ideas que nos pueden servir para comprender algo de la situación política de aquellos convulsos años. Para ello tendríamos que hacer la operación de analizar el documento intentando averiguar los razonamientos y silogismos que hubieran llevado a admitir la posibilidad de que lo que describe el texto tuviera alguna veracidad. Recorrido fáctico por unos hechos descritos por un documento que sabemos que era falso, pero que en cualquier caso encadena una serie de ideas que la maquiavélica mente de Aviraneta engarzó con el propósito de que se descubriese una supuesta conspiración. Esta estrategia personal en cierta medida revela muchos aspectos que entonces estaban en circulación sobre la situación política de la España de 1839, y que Aviraneta no hizo sino publicitar dando pábulo a una falsedad que, con todo, tenía en su seno ciertas dosis de verdad.

Teniendo en cuenta lo anterior ahora podemos pasar a analizar el documento, empezando en primer lugar por el citado Reglamento, que de paso nos sirve para contextualizar el texto atendiendo al momento en que se creó la sociedad; y a los objetivos primeros que se manifestaron en su fundación. Sobre el momento de la supuesta fundación de la Sociedad de Jovellanos, el Reglamento en su articulado nos informa de los objetivos de la organización como un intento de superar la dinámica de los dos bandos contendientes en la guerra. De hecho se cita en el texto de forma expresa la intención de combatir a muerte el despotismo representado en la persona del Pretendiente y los fanáticos que le dirigen y rodean, y por otro el de combatir del mismo modo la anarquía representada por las sociedades secretas y los ministerios que estas engendran. Es una aparente contradicción la que sugiere el texto, presentando una supuesta sociedad secreta que luchaba contra otras sociedades secretas, poniendo de manifiesto la división que existía en la masonería de la época entre dos facciones 
reconocibles. En la presentación de esta contradicción parece ponerse de manifiesto otra demostración de la particular inteligencia de Aviraneta a la hora de dar carácter verosímil a la conspiración. La división de las dos facciones se presume de sobra conocida por los recipiendarios del Simancas, que estarían al cabo de la profunda brecha ideológica entre una facción de la masonería personificada por los comuneros y carbonarios, de un corte más revolucionario y republicano, y otra de un tipo más conservador en términos políticos dentro de la cual se situarían unos jovellanistas supuestamente más partidarios de un acuerdo con los carlistas.

Por otra parte esa alusión expresa a la anarquía reinante se entiende mejor si nos atenemos a las circunstancias del momento, en las que participaban los mayores interesados en esta operación, entre ellos principalmente una regente muy preocupada por el futuro de su hija. Por este Reglamento mencionado antes sabemos que la sociedad se había supuestamente constituido el 20 de noviembre de 1837, es decir, pocos meses después de la promulgación de la Constitución de 1837. Esta constitución fue la piedra angular del partido progresista, de decidido propósito doceañista, y cuya promulgación en un ambiente de verdadero fervor fue muy sentida dentro de los emergentes sectores del moderantismo. Y es que para estos últimos volver a la dinámica establecida en 1812, constituía un peligro, recordando la triste experiencia del Trienio Liberal cuando el hecho de volver a poner en vigor la constitución gaditana atrajo el desafecto de las clases conservadoras. Desde la puesta en vigor de la Constitución de 1837, la conciencia de este peligro se tradujo en un intento por parte de los pensadores menos revolucionarios de volver a una situación más moderada como forma de superar la división ideológica española y ganarse el apoyo de las elites sociales y económicas, aunque esta actitud tampoco colmaba las aspiraciones de los progresistas $^{21}$. El propósito que se marcó la Sociedad como objetivo fundamental fue unir

\footnotetext{
${ }^{21}$ Una buena exposición de estos hechos la tenemos en la obra de Varela Suanzes-Carpegna: "Cuando murió Fernando VII, en 1833, los liberales españoles, divididos ahora en «progresistas» y «moderados», eran en su mayoría partidarios de reconstruir el Estado español a partir de un modelo sustancialmente distinto al de 1812. Diferían, desde luego, en algunas relevantes cuestiones. Pero por encima de estas diferencias unos y otros estaban de acuerdo en construir una Monarquía al estilo de la existente entonces en la Gran Bretaña o en Francia, las dos grandes potencias europeas, a las que España se uniría, en 1834, junto a Portugal, para formar la Cuádruple Alianza. Por otro lado, sólo una Monarquía de esta naturaleza podría contar con el respaldo de la Corona -encarnada entonces en la persona de María Cristina-, y con el apoyo de una parte importante de la nobleza, del Ejército y de la Administración, a cuyo frente se hallaban muchos antiguos «afrancesados», cuyo odio por la Constitución de Cádiz era notorio. La mayoría del Clero, en cambio, se decantó por la causa carlista, lo que sin duda sirvió de pretexto para llevar a cabo, a partir de 1834 y sobre todo de 1837, la desamortización de sus cuantiosos bienes. El nuevo modelo constitucional, se plasmó primero en el Estatuto Real de 1834, aprobado por los «moderados», con la disconformidad de los «progresistas», y después en la muy importante Constitución de 1837, en la que se definió el modelo constitucional vigente en España hasta 1923, al menos en lo que concierne a la organización del Estado, no a los derechos fundamentales. La Constitución de 1837 fue, en realidad, una Constitución «transaccional», elaborada por los progresistas, pero con muchos principios moderados, y destinada a unir a las dos grandes familias liberales frente al enemigo común, el carlismo, que en el mismo año en que se aprobó la Constitución estuvo a punto de entrar en Madrid". Varela Suanzes-Carpegna, J.: La construcción del Estado en la España del siglo XIX. Una perspectiva constitucional, publicado en Bulletin d" Histoire Contemporaine de "Espagne. Des Lumières au libéralisme núm. 37-47 (juin 2004-décembre 2006), pp. 215-225.
} 
los dos bandos en un futuro matrimonio concertado entre un hijo de don Carlos y la entonces niña Isabel II, proyecto que sabemos que efectivamente se estuvo valorando, para así acabar con la división dentro de la estirpe real y favorecer un pacto entre los bandos contendientes. Esta situación política coincidía con la evolución que había experimentado Aviraneta, que a partir de la promulgación de la Constitución de 1837 se había apartado de sus antiguos correligionarios, en el sentido de conceder valor a esa Constitución y abandonar definitivamente opciones más revolucionarias hasta el punto de que llegaría al extremo de denominar a la Constitución de 1837, siguiendo su ya tradicional terminología masónica, nuestro Oriente, nuestro Directorio y nuestra Asamblea ${ }^{22}$. Este brusco viraje traería como lógica consecuencia el que se acusase a Aviraneta de intentar formar una suerte de tercer partido entre los progresistas y los moderados, lo que constituye una posibilidad que parece traslucirse en el texto del Simancas.

Precisamente es en este sentido como se entenderán muchas de las ideas que se expresan en el documento, sobre todo en las cartas donde aparecen continuas referencias al caos del gobierno progresista. Esta situación de crisis se intentaba subvertir intentando acabar con la guerra, pero de paso también con los sectores que apoyaban ese emergente progresismo, empezando por Espartero y siguiendo con Mendizábal, ambos enemigos personales de Aviraneta. $\mathrm{Y}$ es que Aviraneta, persiguiendo un ideal personal un tanto megalómano, se estaba empezando a ganar las antipatías de todos los partidos en liza, lo que se hace constar en un texto lleno de veladas invectivas contra la ideología progresista. Pero también se nota en las continuas críticas al gobierno progresista del Simancas un intento de dar cierta verosimilitud al texto, siguiendo lo que parece era un guión muy pensado por Aviraneta con este ánimo. Empezando por la idea de que, en términos convencionales, la sociedad del momento parecía atribuir a la facción más conservadora de la masonería cierta connivencia con los sectores moderados. Esta idea que reforzaría el lógico sentido de la existencia de un núcleo jovellanista en el bando carlista, que se entendería como consecuencia de un clima de entendimiento de ciertos sectores del carlismo con el partido moderado actuando la Sociedad como enlace entre ambos, lo que podría ser perfectamente comprendido por los más acérrimos defensores de una causa tradicionalista en horas bajas. Esta estrategia encaja a la perfección en la vida de un Aviraneta siempre llamado a intentar superar las rivalidades que pensaba podían precipitar el fracaso de la causa liberal, y que en todo caso configura el texto del Simancas más allá del

22 Así aparece esta situación descrita en su "Vindicación de don Eugenio de Aviraneta de los calumniosos cargos que se le bicieron por la Prensa con motivo de su viaje a Francia en comisión de gobierno; Y observaciones sobre la guerra civil en España y otros sucesos contemporáneos”. Ed. N. Sanchiz, Madrid (1838). La cita indicada aparece en el Apéndice a la vindicación..., Ed. Lamaignere, Bayona (1838) p. 15. 
interés en darle cierta apariencia de verosimilitud para acabar siendo una perfecto escaparate de las ideas de su autor.

Este marco de relaciones entre las ideas políticas comunes y las personales de Aviraneta va más allá de sus deseos de dar esa apariencia de veracidad al texto del Simancas. Las feroces críticas al comandante en jefe del ejército isabelino que veremos aparecer en el expediente, van a ser una constante explícita en la correspondencia, lo que vuelve a poner de manifiesto las fobias un tanto recurrentes de un Aviraneta enemistado con Espartero. Esta animadversión manifiesta contra Espartero descrita con meridiana claridad, tiene por objeto seguramente un intento de que los carlistas vieran en el triunfo moderado una solución intermedia que pudiera satisfacer algunas de sus pretensiones. Este sentimiento que, por otra parte, ya se había extendido dentro del campo carlista, sin duda ayudaba a dar mayor credibilidad al Simancas. Inteligente dinámica a la que podemos unir las espinosas relaciones del citado Espartero con Aviraneta. Eran enemigos irreconciliables hasta el punto de que el general en algunas ocasiones ordenó su detención e incluso su fusilamiento, siendo este frustrado sin embargo.

Pasando al núcleo del Simancas, que está constituido por una serie de cartas supuestamente enviadas desde Madrid a Bayona, podemos hacer un análisis de ellas siguiendo la descripción de los hechos que cuentan. Con ello podemos hacer el mismo ejercicio que seguramente harían don Carlos y sus seguidores cuando viesen ese documento, ejercicio que acabaría con la conclusión de que participó en esa conspiración. Las cartas son un total de 22, fechada la primera el 5 de enero de 1839, y la última el 10 de mayo de 1839, poco antes de que llegara este documento al bando carlista. Están numeradas, siendo la primera la que tiene el número 67 y la última el 88 , con lo que se supone que las anteriores serían las que se hubiesen expedido desde la fundación de la sociedad a fines de 1837. En ellas se empieza por felicitar al desconocido receptor de las cartas por el éxito que estaba consiguiendo al ver la organización extenderse por el territorio de las cuatro provincias bascongadas bajo control carlista. Buenos augurios que empezamos a encontrar con mayor profusión, estando todos los miembros de la Sociedad alistados en dos Triángulos denominados de forma genérica como los amigos. El primero con la denominación de Triángulo del Ejército del Norte es el que estaba introducido en el bando isabelino. El segundo al que se nombra como Triángulo del otro campo es el del bando carlista.

Siguiendo con el hilo argumental, y ya con la suficiente acreditación de la extensión y buen funcionamiento de la Sociedad ya introducida en el bando carlista, el 15 de enero se empieza a hablar de la preparación de un golpe de terror. Para lo cual se comunica 
desde la Dirección General que los amigos podían contar con todos los fondos que se necesiten para la empresa, así como de dice que no se preocupasen por el resultado de la misma porque si se viesen obligados a emigrar se les suministrará lo necesario para que se mantengan con el decoro a que son acreedores. Con esta idea empezamos a ver aparecer en las cartas referencias muy explícitas a ciertos tópicos de la masonería. Entre ellos las grandes cantidades de dinero que movían estas hermandades y la facilidad con que lo obtenían. Así, la primera alusión que se hace a una remesa de dinero es del 25 de enero, cuando se dice que se había enviado la enorme cantidad de quince mil duros, lo que dice mucho de las posibilidades económicas de los jovellanistas. O como cuando, tras los sucesos de Estella, se dice que se enviarían inmediatamente cinco mil francos a los amigos según consta en carta de 10 de marzo. El movimiento de dinero se realizaba con mucha facilidad porque la Sociedad estaba instalada dentro de una poderosa red europea, como da a entender la indicación de que la casa de $\mathrm{R}$. $S$. podía proveer todo lo necesario. Ello parece una alusión directa al banco Rothschild \& Sons que entregaría al agente receptor de las misivas seis mil francos, lo que al menos nos sirve para comprobar que ya en aquellos años se atribuía a esta poderosa familia unas inauditas capacidades. Estas alusiones a una poderosa red internacional son continuas, justificándose a causa de un supuesto interés de los magnates europeos por que triunfase el moderantismo en España.

Más interesantes resultan las comentadas alusiones a Espartero, al que la Sociedad deseaba quitar de en medio como líder que era de la facción progresista, y en las que parece quizá verse demasiado la animadversión que sentía Aviraneta por él. En este sentido el 20 de enero ya se indica que la sociedad estaba tomando las precanciones necesarias que inhabiliten $y$ adormezcan a Espartero. O como en la carta del 29 de enero, en la que se indica que no se celebre ninguna clase de avenimiento ni transacción con Espartero, a quien se está anulando por los Triángulos del Ejército y los periódicos. Se insistía en la idea de que el control del general era total, tal y como puede colegirse de la carta del 17 de abril cuando se afirma taxativamente que Espartero no atacaría al bando carlista tras los sucesos de Estella; o de la de 20 de enero donde se indica que la deserción en las filas de nuestro ejército marcha en progresión. Ese mismo control también se decía llegaba al ejército carlista y que también era total según el Simancas. Encontramos también alusiones directas al hecho de que desde la Sociedad se había conseguido situar a miembros de ella al mando de los Batallones Castellanos de ese bando, que ciertamente habían empezado a desertar de la causa carlista coincidiendo con las fechas de las cartas que referencian el asunto. 
El ambiente de descomposición del bando carlista es una idea que preside el texto, y que resulta muy significativa, como demostrarían los planes que estaba urdiendo la Sociedad en connivencia con las elites vasco-navarras, los llamados en las cartas amigos del interior. De hecho una referencia explícita a las conversaciones de mayo-junio de 1839 que acabarían en el Convenio de Oñate firmado el 29 de agosto, antesala del Abrazo de Vergara, se cita en la carta de 29 de enero. Lo que vendría a demostrar que ya entonces se estaba urdiendo desde el bando isabelino el plan de llegar a un acuerdo con el bando carlista, solución al conflicto que era contemplada como una victoria por unos jovellanistas que no dudaban en atribuirse el mérito. Este ambiente de entendimiento reinaba en las aparentes conversaciones presididas por un ambiente de connivencia y complicidad mutua, al margen de los jefes principales de los bandos en contienda, y que revelan unas ideas muy singulares acerca del papel de las citadas elites vasco-navarras. Y es que, para conseguir este propósito en esa citada carta, se dice que los amigos en sus conversaciones con los paisanos del territorio carlista no alteren en lo más minimo el actual orden de cosas esistente en las Provincias Bascongadas. Esta era una alusión directa a la decisión de respetar el derecho foral vasconavarro para contentar a los provincianos, y particularmente a los interesados en los privilegios, pues la ayuda y cooperación de la nobleza nos serán del mayor apoyo en el segundo tránsito de la contrarrevolución. Si esta idea expresada era la común entre el bando isabelino, la verdad es que deja en muy mal lugar, si no el exacto papel de las elites vasco-navarras en el contexto de la búsqueda de una paz, sí al menos el que les atribuía la opinión pública, si es que esta era la idea que parece traslucirse en el Simancas. O así al menos era para Aviraneta, descendiente al fin y al cabo de linajes vascos, que no demostraba tener mucha simpatía por sus paisanos, a los que en general catalogaba de fanáticos reaccionarios salvo honrosas excepciones.

En cuanto al asunto de las circunstancias ideológicas en las que supuestamente se movía la Sociedad de Jovellanos y que enmarcaban su actividad política, hemos destacado su determinante papel de dirección del moderantismo. Esta idea se remarca continuamente en todas las cartas, como por ejemplo cuando se dice el 29 de enero que había que deshacerse de los furibundos de ambos partidos, entendiéndose este aserto como los propósitos de los jovellanistas de superar la rivalidad entre el ideario revolucionario progresista y los anhelos de los carlistas por resucitar el antiguo régimen. Acción esta para la que se contaba con el supuesto apoyo de la Europa moderada, y para la que la organización según la carta de 5 de febrero ejercía un poderoso influjo por la mayoría que tiene en las Cortes como forma de mediatizar al gobierno del entonces presidente Pérez de Castro, ya fuera en ese órgano o desde sus periódicos. Esta capacidad de acción queda remarcada en esa misma carta, cuando se expresa 
que la administración del Gobierno volverá de nuevo a manos de la Sociedad tras derrocar al mencionado presidente. El control de los instrumentos titulares de la soberanía constitucional está verdaderamente fuera de la realidad, aunque parece demostrarse con estos comentarios que existía entre ciertos sectores de la opinión pública el sentimiento de que el gobierno central estaba en manos de supuestas sociedades secretas. Esta idea general más parece un deseo que una verdad evidente, y parece dar carta de naturaleza a los deseos de nuestro Aviraneta de dar ocasión a su fantástico proyecto de crear una suerte de tercera vía, deseo este expresado en las cartas con una crudeza hasta cierto punto de vista infantil, que podrían demostrar que Aviraneta, si es que son realmente sus propias opiniones las que aparecen en el texto, estaba bajo el influjo de una personalidad trastornada cuyos perfiles extremadamente megalomaniacos estaban empezando a situarle fuera de la realidad.

Mucho más se puede escribir sobre las ideas expresadas acerca de las capacidades e influencia de los jovellanistas, verdadero paradigma de una sociedad secreta dedicada a la conspiración. Pero ahora debemos centrarnos en el asunto del general Maroto y la preparación de los fusilamientos de Estella, objetivo último del documento en su interés en demostrar la pertenencia del citado a la Sociedad. Y es que, como sabemos, Maroto el 18 de febrero de 1839 ordenó el fusilamiento de los generales Guergué, García, Sanz Baeza, y el intendente Úriz. Este suceso marcó la definitiva descomposición del bando carlista y fue provocado a juicio del Simancas conforme a los preparativos que exponemos a continuación.

Ya en la carta del 15 de enero se habla de la necesidad de dar un golpe de terror, aunque se exige guardar el mayor sigilo para que no se trasluzca la intervención de la Sociedad en cualquiera acto sangriento que ejecuten los amigos. Se había ordenado la ejecución de este plan en la tenidda de enero sin explicitarlo expresamente, mientras que en la carta de 9 de febrero se indicaba a los amigos que no se preocupasen por llevarlo a cabo, pues sean cuales fueren los sucesos que ocurran en el otro campo, el ejército de la Reina se mantendrá a la expectativa sin emprender ninguna operación. La inacción del ejército isabelino con cuya alusión Aviraneta intentaba conceder algo de veracidad a su complot, de hecho ocurrió, lo que provocó cierto estupor en la opinión pública. En este contexto a tenor de las cartas quedó todo preparado, hasta que en la carta del 14 de febrero, exactamente cuatro días antes de los fusilamientos, se dice que el Director General manifestaba que sabía que se acerca la tormenta, y que se estaban adoptando las medidas para que el triunfo sea el más completo. 
Es a partir de entonces cuando las alusiones a Maroto empiezan a ser directas, con toda una serie de referencias a hechos que realmente ocurrieron. De ellas destaca la que aparece en la carta de 22 de febrero, donde se dice que este supuesto presidente de la facción carlista había llegado a Tolosa en compañia de los amigos, desde donde había salido a Vergara dentro del Ejército Real, movimiento que se califica como de precursor del grande acontecimiento y que los informes de la guerra certifican que efectivamente se realizó. Pero la más explícita es la de la carta de 26 de febrero, ocho días después de los fusilamientos, donde se dice que se ha recibido la carta del presidente del Triángulo del Ejército del Norte asegurando que el presidente del Triángulo del otro campo fusiló el 18 de este mes en Estella a los cuatro jaques mayores. Esta es una alusión explícita a Maroto, al que se le llama también amigo mayor y al que se le dedican todo tipo de alabanzas. Este hecho singular debía servir de oportunidad para imponer la ley a los charlatanes y fanáticos de ambos partidos, y para que así la Sociedad pudiese contribuir decididamente a su propósito de establecer de hecho el sistema moderado. El mismo reconocimiento de la supuesta presidencia de Maroto de su Triángulo que se hace en la carta de 28 de febrero, cuando se dice que se ha recibido la proclama que hizo el amigo mayor al pueblo y las tropas en Estella el 18 de este mes, y su carta del 20 a don Carlos. De esta carta se dice que fue preparada personalmente por el propio secretario de la Sociedad cuyo nombre desgraciadamente se cita en clave.

Tras los sucesos citados, como hemos indicado, la defección en el bando carlista empieza a ser total. Así, en la carta de 15 de marzo, se empieza a hablar de los soldados y colaboracionistas que estaban emigrando a Francia, y de las deserciones en el seno de los Batallones $5^{\circ}$ de Guipúzcoa y $5^{\circ}$ de Navarra, mientras que el Director General se queja de que Maroto no hubiese fusilado también a los generales Ibero e Iturriza. Mientras tanto la Sociedad estaba empezando a crecer tras los fusilamientos, según se reconoce en la carta de 25 de marzo y como se vuelve a reafirmar en la de 20 de abril. Estas son referencias explícitas de Maroto a las que se acompaña otra más indirecta, como cuando la carta de 12 de abril habla de que en el artículo de Diego Miguel García firmado con el seudónimo de El Faro del día 2 de ese mes, se habla mal del amigo mayor. Ese artículo efectivamente fue publicado en El Eco del Comercio, órgano de expresión oficial del liberalismo exaltado, y en él se habla de los sucesos comentados y del general Maroto.

Pero la conspiración no quedaba en estos hechos, y todo parecía indicar que se estaba preparando otra decidida acción antes de que el Simancas cayera en manos de don Carlos. De hecho en la carta del 17 de abril se dice que se averiguase por parte del agente que efecto causaría en las tropas y en el pueblo la desaparición de don Carlos por medio de otro golpe como 
el de Estella. Desaparición sobre la que se vuelve a insistir en la carta del 20 de abril, cuando se ordena por la Dirección General la desaparición de don Carlos con otro golpe como el de Estella. Para la consecución de esta acción se informa de que se librarían las cantidades que fuesen necesarias por crecidas que sean. Con este interés en remarcar este hecho, el inteligente Aviraneta seguramente buscaba el que don Carlos, o con más seguridad las personas más próximas a él, realizasen alguna expeditiva respuesta que viniese a sembrar todavía más el caos en el bando carlista.

Para efectuar una evaluación de los resultados de la acción de Aviraneta nos vemos enfrentados entre los comentarios de su autor, que siempre defendió que el Simancas fue decisivo para el Abrazo de Vergara, sin cuyo concurso este acuerdo de paz nunca hubiera podido celebrarse. El resto de los interesados, negaron siempre que su autor hubiese nunca tenido éxito en sus labores de agente y espía, y redujeron su actividad a simples y mediocres enredos. De hecho Aviraneta nunca pudo evaluar sobre el terreno el resultado de la obra porque fue sacado precipitadamente de Bayona los días previos a la confirmación del Convenio de Oñate, lo que no es de extrañar teniendo en cuenta que tanto Espartero como seguramente Maroto por razones obvias eran declarados enemigos suyos, o al menos podían ver con cierto reparo su molesta presencia en medio de unas delicadas conversaciones ${ }^{23}$. Esto le provocaría a Aviraneta un enfado monumental, en proporción seguramente a la frustración que le atenazaría por verse relegado en pro de Espartero $^{24}$. De este modo no se nos permite saber las exactas consecuencias que toda esta aventura del Simancas pudo tener, y así valorar el definitivo resultado de ella, aunque el propio Aviraneta afirmaría siempre que fue eficacísima y determinante. El apartamiento provocó la queja expresada por Aviraneta en su citada Memoria, en la que por otra parte, pese a reconocer lo falso del citado expediente, extrañamente nunca citó expresamente el verdadero nombre de la Sociedad. Esta circunstancia nos permite saber que Aviraneta, quien

\footnotetext{
23 "Consecuencia de esta doble situación de descrédito en Aviraneta y de reparo en abandonarlo por parte de los que lo empleaban, resultó que al ser enviado por la Reina y por Pita para entablar sus trabajos de zapa contra el carlismo (esta es una buena definición de la misión de Aviraneta), sujetaron a su hombre de confianza a una dependencia y fiscalización del cónsul de Bayona, que hasta cierto punto coartaba la libertad de acción de Aviraneta y perjudicaba al éxito de sus trabajos. Espartero y sus generales, igualmente prevenidos contra el agente secreto, desautorizaban y estorbaban de mil maneras la espontaneidad de sus movimientos; circunstancias todas estas que dan mayor valor a los servicios de Aviraneta, los que, como se verá, no fueron estériles y antes al contrario contribuyeron a la venturosa catástrofe que lanzó a don Carlos del territorio español, sin que deba dejarse de tener en cuenta que los amigos de Aviraneta le atribuyen en el éxito de los trabajos que condujeron al tratado de Vergara, una participación que fue en gran parte obra y efecto de hechos ajenos a la inmediata y directa acción del agente secreto”. Ob. cit. 13 vol. VI pp. 292-293.

24 Estos terribles sentimientos se perciben en dos cartas que remitiría a la regente. En una de ellas reivindicando el papel determinante que había tenido él para llegar al Convenio y que aparece en la referencia AGP Sección Reinados Fernando VII caja 17 exp. 20. La otra es un exhaustivo memorial que recoge los hechos de su heroica misión, AGP Sección Reinados Fernando VII caja 33 exp. 1.
} 
de algún modo se había encargado de divulgar en los círculos políticos la existencia de la hipotética Sociedad de Jovellanos, seguiría dando publicidad a la misma. La organización quedaría convertida en una singular herramienta para sus enredos futuros, toda vez que había puesto en marcha una invención a la que se podía atribuir la autoría de los más extraños sucesos como forma operativa de participar desde las sombras de la actividad política al albur de sus particulares intereses fuesen cuales fuesen ${ }^{25}$.

Pero lo más interesante es que aparecen otros interesados en promover la supuesta existencia de esa Sociedad, hasta el punto de que su existencia pasaría a formar parte de la leyenda política de la época sin que nadie en esos años llegase a poner nunca en duda la existencia del poderoso e influyente núcleo de los jovellanistas. De hecho las alusiones a los jovellanistas van a empezar a ser una constante a partir de esos años, como demuestra el sorprendente hecho de su cita por el propio Espartero en su autobiografía publicada en 1846, donde se habla de la Sociedad Jovellanos en estos términos: a los moderados se les llamaba sarcásticamente Los de la suprema inteligencia... Fácil es calcular hasta dónde hubiesen llegado las pretensiones, y hasta dónde los efectos del vasto plan que hace mucho tiempo se fraguan, según la voz.publica en la tenebrosa Sociedad, que la misma señala con el nombre de Jovellanos ${ }^{26}$. Hecho singular que resulta muy extraño, si tenemos en cuenta que Espartero debió conocer la intervención de Aviraneta en el asunto del Simancas, con lo que se demuestra que seguramente el general hacía uso de la pretendida existencia de esta Sociedad como un pretexto para sus planes políticos personales, toda vez que podría adjudicarle acciones interesadas justificándolas como producto de una desconocida y misteriosa sociedad secreta. Este uso torticero de la organización pareció compartirlo Espartero con Aviraneta, hasta el punto de que hoy nos sería difícil distinguir cuál de los dos fue el verdadero causante de la aparición en las fuentes de la Sociedad de Jovellanos. Este elemento viene a reafirmar nuestra tesis de que las supuestas conspiraciones de imaginadas sociedades secretas eran un arma política. Un instrumento tan típico y hasta cierto punto de vista lógico para sus tiempos, que era usado indiscriminadamente y sin ninguna cortapisa por todos los participantes de la vida política,

\footnotetext{
25 “El propio día regresé a Bayona, y el agente secreto del cónsul que entró en Behobia en el mismo carruaje, me acompañó hasta aquella ciudad; y habiendo pasado yo, luego que me apeé de la diligencia, a comunicarle el resultado de la operación, lo encontré encerrado con Nenin, que se anticipó indudablemente a dar cuenta de la importante comisión que acababa de desempeñar contra mí. Precisamente cuando más indispensables eran toda mi lealtad, patriotismo y constancia para llevar a cabo el mayor de todos los servicios que en los seis años de guerra se han prestado a la causa de la Reina y de la patria, los delegados del gobierno de esta me hacían sufrir tanta humillación y amargura, que bien parecía deseaban obligarme a abandonar mi grande empresa". Ob. Cit. 8 p. 55.

${ }^{26}$ Espartero, páginas contemporáneas escritas por él mismo, y precedidas de un prólogo por Eduardo Chao, Imp. de Julián Saavedra y Compañía, Madrid (1846) p. 74.
} 
como consecuencia lógica de los viejos principios de la razón de estado según los cuales el fin justifica siempre los medios.

Esta idea parece ser de algún modo compartida por el otro interesado en la cuestión, como fue el general Maroto. Precisamente en su conocida Vindicación que publicaría en 1846, y con la que intentaría justificar su denostada biografía vital, dedica el general muchas reflexiones a nuestro Aviraneta, al que califica como un egocéntrico movido por intereses de vanagloria y fama. En este punto se nota el profundo desprecio que le causaba a Maroto su entonces desaparecida figura ${ }^{27}$. Varias referencias aparecen sobre él, empezando por una crítica feroz a su citada Memoria, a la que dedica nada menos que todo un capítulo de esta obra en el que hace una pormenorizada catalogación de todos los agravios provocados por las irreflexivas acciones de Aviraneta ${ }^{28}$. Pero lo que puede llamar la atención son dos cuestiones concretas que se muestran en esta obra citada. La primera es que para Maroto, Aviraneta, desde los comienzos, estaba dentro de los planes políticos del Gobierno de Madrid y de los propios del bando de Espartero, que se habían puesto de acuerdo en enviarle como agente de ambos, lo que parece contradecir animadversión de estos personajes. Por este comentario a lo mejor se podía entender lo que hemos citado sobre la connivencia de ambos en mantener la vida de la Sociedad de Jovellanos, al menos en el sentido, que de momento no podemos aclarar, de que a lo mejor Espartero supo desde el primer momento del plan de Aviraneta e incluso de algún modo pudo

\footnotetext{
${ }^{27}$ Vindicación del general Maroto, y manifiesto razonado de las causas del Convenio de Vergara y demás sucesos notables que les precedieron, justificados con cincuenta documentos, inéditos los más. Ed. Imprenta del Colegio de Sordomudos, Madrid (1846).

${ }^{28}$ En el citado Capítulo I de la Parte segunda dedicado a Aviraneta y a Michell podemos destacar los siguientes párrafos: "Bajo el título de planes y operaciones puestos en ejecución para aniquilar la rebelión carlista en las provincias del norte de España, publicó D. Eugenio de Aviraneta un folleto que patentiza los medios de que echó mano el gobierno de Madrid en aquella época, para combatir con la política una causa que tanto le daba que hacer con las armas. El señor de Aviraneta tiene por grande gloria el haber dirigido este asunto, pretende ser el autor del pensamiento de transacción ó de paz y aspira al lauro que de la pacificación de las provincias del Norte pueda caber á sus esfuerzos; no intento rebajarle en lo más mínimo sus persuasiones, pero si observaré en primer lugar que, el deseo de paz y transaccion tuvo su origen mucho tiempo antes que la comision de Aviraneta, que si bien es cierto contribuyó con sus manejos á precipitar los resultados, quizá sin aquellos hubiesen nacido otras combinaciones más ventajosas al servicio de la reina, y que la pacificacion ó el convenio ni fué obra de Aviraneta ni de otro alguno; pues segun y he dicho la influencia moral de los sucesos es la que manda á los hombres, y estos por mas hábiles directores que se crean, no son sino instrumentos que obran y proceden en todos sus actos bajo el dominio de aquellas... ¿qué hubieran producido los manejos de Aviraneta? Algunas víctimas ú odios parciales, pero al fin hubiesen sido descubiertos y estos aislados esfuerzos no hubieran llegado jamás á dividir totalmente á los carlistas". Ibíd. p. 256. "Habla el autor de la memoria de dos cartas que me escribió y que puedo asegurar no llegaron á mis manos, así como ser incierto que hubiese sostenido comunicacion el Sr. De Aviraneta con jefe alguno del ejército carlista". Ibíd. p. 257. "Ciertamente que el señor de Aviraneta con sus manejos (de los cuales solo manifiesto una corta parte) pudo influir de algún modo en los procederes de D. Cárlos, pero no en los mios que, repito no recibí sus maquiavélicos escritos, y que regularmente los hubiera adivinado, y calificado tales aunque hubieran llegado á mi poder, pues solo los personajes que creen en agüeros y vaticinios de monjas pueden dar crédito á papeles anónimos ó firmados por personas desconocidas; solo los que ven un traidor en cada servidor fiel pueden dar acogida á instigaciones que aumenten sus desconfianzas”. Ibíd. pp. 261-262.
} 
estimularlo. Esta situación supondría todo un cambio en las relaciones de estos personajes tal y como han llegado a nosotros, y en cierto sentido podría adquirir un nuevo sentido si pensamos que a ambos en el fondo les unía una colaboración más allá de sus sentimientos mutuos, lo que al final vendría a dar peso a la posibilidad de que la conspiración denunciada por el Simancas realmente tuviera algo de verdad en medio de su inverosímil artificio al margen de su verdadera naturaleza. Pero la segunda cuestión es todavía más curiosa, y es que Maroto, en medio de la crítica feroz a Aviraneta, no hace la más mínima referencia a los papeles del Simancas. Si realmente Maroto quería ridiculizar a Aviraneta tendría con este asunto material de primera. Las razones para este premeditado olvido pueden dar pie a muchas posibilidades, entre otras que Maroto hubiese caído en la cuenta de que Espartero y Aviraneta trabajaron juntos en la preparación de este complot. Pero también de que el Simancas quizá ocultase alguna verdad que le resultase especialmente molesta.

Con todo esto tenemos establecida una paradoja que daría pie a dos posibles valoraciones que pueden convertirse en conclusión final de este trabajo. Estos dos elementos de juicio no son necesariamente contradictorios, pudiendo ambas posibilidades estar presentes en la acción del Simancas al dictado de las particulares personalidades de sus instigadores, lo que es de especial valor sobre todo para el complejo Aviraneta. La primera valoración parte de la consideración de que los tres interesados directos en el asunto del Simancas coinciden en un punto fundamental, teniendo en cuenta que los tres conocieron la falsedad del complot. Empezando por un Espartero que siguió usando el nombre de los supuestos jovellanistas y que nunca hizo explícita la falsedad de su existencia, siguiendo por un Maroto que tampoco nunca reconoció el artificio del Simancas y por último acabando con un Aviraneta que reconoció la falsedad del mismo pero nunca citó a los jovellanistas. Todos parecieron estar muy interesados en que nunca se supiera la exacta verdad del asunto, quizá porque pudieron haber compartido algún propósito común. Todas estas circunstancias nos permiten aventurar una hipótesis, concediendo al lector el valorarla adecuadamente, esto es, intuir que la historia general del Simancas, la existencia al fin y al cabo de una conspiración introducida en el bando carlista tuviera algo de real al margen de los partícipes en ella y de su exacta naturaleza.

Esta cuestión podría haber ido acompañada de otro segundo matiz y no del todo contrario a la anterior valoración que hemos hecho, pensando en que fuese verdaderamente la elaboración del Simancas una acción estrictamente personal de Aviraneta, lo que por otra parte es la tesis oficiosa que ha llegado a nosotros a través de su autor. En este caso Aviraneta lo que hizo fue poner negro sobre blanco lo que por otra parte era un rumor 
muy extendido, como fue el de las conversaciones que se estaban manteniendo entre Espartero y Maroto buscando el final de la guerra. En esta situación, y si descartamos lo que hemos dicho acerca de una posible colaboración de Espartero con Aviraneta, el lógico objetivo personal que quizá este último buscaba no sería tanto sembrar el desconcierto en el bando carlista, que ya estaba en verdadera descomposición, como intentar sustraer a Espartero su más que anunciada victoria escenificada después en Vergara ${ }^{29}$. Con esto se pondría de manifiesto el visceral odio que parecía sentir Aviraneta por Espartero, que llegaría al extremo de preparar un complot, sin importarle que lo estrictamente masónico del mismo adquiriese unos matices absurdos según su intención de que la conspiración respondiese a unas ideas convencionales. Aunque hay que tener en cuenta nuestra impresión obre el aparente interés de ambos en ocultar la verdad del asunto cosa que, de ser cierta, no parece encajar del todo con el odio mutuo que se profesaban.

En cualquier caso las dos posibilidades resultantes de la estrategia del Simancas, parecen encajar con el carácter de Aviraneta y desde luego con el de aquellos convulsos años, uno de cuyos agentes más activos en la vida política eran las conspiraciones de sociedades secretas como las logias masónicas ${ }^{30}$. Estas conspiraciones que tal y como hemos señalado eran un medio de participación activa en unos momentos en que las vías convencionales de expresión política estaban todavía en formación. A lo que se añade que en las circunstancias históricas de esa época en transformación, los medios de expresión que hoy nos parecen fuera de lugar en las democracias avanzadas resultaban entonces instrumentos que se consideraban legítimos por sus interesados usuarios. Es por lo tanto en este ámbito como se entiende que el uso de un arma inteligente como la de la invención de una supuesta conspiración, fenómeno típico de aquellos tiempos, pudiese dar ocasión con cierto aire de legitimidad a que un hombre como el gran conspirador Aviraneta, en la

\footnotetext{
${ }^{29} \mathrm{El}$ General Espartero pronto se quejaría de que muchos estuvieron intentando ganarse el mérito del Convenio de Vergara, "Aquellos sucesos felices, [que] fueron obra exclusivamente mía”, mérito personal que el propio Gobierno estaba intentando monopolizar, como también hizo gala el gobierno francés, que presumía de haber llegado a ese acuerdo por la intervención del mariscal Soult en nombre de la Cuádruple Alianza. Cita en Espartero, B.: Epistolario de la primera guerra civil española: campañas del General Espartero. Recopilado por el Marqués de Morella, Ed. Familiar, Madrid (1951-1952) Tomo II, págs. 52-54bis y 65.

30 Situación que se sumaba a la de la mala relación de Espartero con la regente: "La relación entre ambos se empezó a torcer justo a partir de entonces debido a las cosas de la política. Espartero se opuso a la disolución de las Cámaras que ella sí respaldó, "pues creía que venían buenas las Cortes", montó en cólera debido a los ascensos de Llauder y el barón del Solar, y explotó definitivamente al saber por su mujer, quien lo supo a su vez por Van Halen, que Aviraneta se atribuía los méritos del Convenio de Vergara en su memoria, cuando a juicio de ella, la única que se leyó el texto de los cuatro, era justo lo contrario, pues lo alababa mucho, lo ponía en las nubes". Ibíd. p. 476.
} 
más absoluta soledad y al margen de sus razones íntimas, pudiese atreverse a alterar el curso de la Historia, o al menos tener la osadía de intentarlo ${ }^{31}$.

\section{BIBLIOGRAFÍA}

ÁLVAREZ LÁZARO, P. F., La masonería, escuela de formación del ciudadano. Ed. Universidad Pontificia Comillas, Colección del Instituto de Investigación sobre Liberalismo, Krausismo y Masonería, 13, Madrid (2005).

AVIRANETA, E. de, Contestación de Aviraneta a los autores de la. vida politica y militar del general Espartero, duque de la Victoria”, Madrid (1864).

ID., Memoria dirigida al gobierno español sobre los planes y operaciones puestos en ejecución, para aniquilar la rebelión en las provincias del norte de España”. Ed. Imprenta de don Narciso Sánchiz, Madrid (1844).

ID., Vindicación de don Eugenio de Aviraneta de los calumniosos cargos que se le bicieron por la Prensa con motivo de su viaje a Francia en comisión de gobierno; Y observaciones sobre la guerra civil en España y otros sucesos contemporáneos". Ed. N. Sanchiz, Madrid (1838).

ID., Apéndice a la vindicación publicada por Don Eugenio de Aviraneta en 1838”, Ed. Lamaignere, Bayona (1838).

BAROJA, P., Memorias de un hombre de acción. Ed. Círculo de Lectores, Barcelona (1997) 3 vols.

ID., Aviraneta o la vida de un conspirador. Ed. Espasa Calpe, Madrid (1978).

BUSQUETS, J., Las sociedades secretas militares en la primera transición española: La Isabelina (1833-1836). Publicado en Masonería, revolución y reacción, vol. 1, coord. Ferrer Benimeli, Madrid (1990).

CASTILLO PUCHE, J. L., Memorias intimas de Aviraneta o manual del conspirador. Ed. Biblioteca Nueva, Madrid (1952).

DE DIEGO GARCÍA, E.; -Aproximación al estudio de los posibles masones en 1823. En La masonería en España en el siglo XIX, vol. 21987 pp. 451-466. Coord. Ferrer Benimeli, J. A.

\footnotetext{
${ }^{31}$ El carácter general de la intervención de Aviraneta y su Expediente Simancas siempre ha formado parte de una hipotética Historia de la Conspiración. Así ha llegado a nuestros días como se refleja en el artículo de Urquijo Goitia, J. R.: Los servicios de información en la Primera Guerra Carlista. Publicado en el volumen Los servicios de información modernos y contemporáneos de la Revista de Historia Militar. Ed. Instituto de Historia y Cultura Militar, año XLIX (2005) pp. 81-132. "En Las figuras de cera dedica una parte del texto a la descripción del dossier «Simancas», con el que supuestamente logró hacer estallar las rencillas en el campo carlista, hasta abocarlo a su descomposición. Se empezó con la introducción de escritos falsos, que podían alentar la resistencia a la guerra, cuyo peso resultaba insoportable... Las páginas relativas al expediente «Simancas» son el culmen de la actuación del servicio de inteligencia: se crean una serie de documentos falsos con ánimo de sembrar la discordia; se impide la negociación de un empréstito, etc.” Ob. cit. pp. 96-97.
} 
Actas del Simposium de Metodología Aplicada a la Historia de la Masonería Española, Salamanca (1985).

FERRER BENIMELI, J. A., Implantación de logias y distribución geográfico-histórica de la masonería española” p. 58. Publicado en La masonería en la España del siglo XIX”, Actas del Simposium de Metodología Aplicada a la Historia de la Masonería Española, 2 (1985) Salamanca pp. 57-216.

DE LA FUENTE, V., Historia de las sociedades secretas antiguas y modernas en España y especialmente de la Francmasonería. Imprenta a cargo de D.R.P. Infante, Madrid (1874-1882).

ESPARTERO, B., Páginas contemporáneas, escritas por él mismo, y precididas de un prólogo por Eduardo Chao”. Ed. Imp. de Julián Saavedra y Compañía, Madrid (1846).

ID., Epistolario de la primera guerra civil española: campañas del General Espartero. Recopilado por el Marqués de Morella. Ed. Familiar, Madrid (1951-1952).

GARCÍA ROVIRA, A. M., Eugenio de Aviraneta e Ibargoyen (1792-1872). El paroxismo de la conspiración”. Publicado en Liberales, agitadores y conspiradores: biografías heterodoxas del siglo XIX coord. por Isabel Burdiel Bueno, Manuel Pérez Ledesma, Ed. Espasa Calpe, Madrid (2000).

LAFUENTE, M.: Historia General de España. Desde los tiempos primitivos hasta la muerte de Fernando VII. Continuada desde dicha época hasta nuestros días por Juan Valera, con la colaboración de Andrés Borrego y Antonio Pilara. Barcelona, Ed. Montaner y Simón (1877-1882).

MAROTO, R., Vindicación del general Maroto, y manifiesto razonado de las causas del Convenio de Vergara y demás sucesos notables que les precedieron, justificados con cincuenta documentos, inéditos los más. Ed. Imprenta del Colegio de Sordomudos, Madrid (1846).

MORAL RONCAL, A. M., "El Infante don Francisco de Paula Borbón: masonería y liberalismo a la sombra del trono". Investigaciones históricas: Época moderna y contemporánea, $\mathrm{n}^{\circ} 20$ (2000).

ORTIZ-ARMENGOL, P., Aviraneta o la intriga. Ed. Espasa Calpe, Madrid (1994).

PIRALA, A., Historia de la guerra civil y de los partidos liberal y carlista. Madrid (18681869) Imprenta señores P. Mellado, vol. V.

PLANTADA Y AZNAR, J., Carlismo y Masonería: tácticas alucinantes”. Ed. Prensa Española, Madrid (1972).

ID., Liberalismo y Masonería: fraudes intelectuales". Ed. Prensa Española, Madrid (1973).

ID., Fernando VII y la Masonería: españoles, unión y alerta”. Ed. Prensa Española, Madrid (1973). 
SIMÓN PALMER, Ma del C., "El espionaje liberal en la última etapa de la Primera Guerra Carlista, nuevas cartas de Avinareta y de F. de Gamboa". Cuadernos de Historia, tomo IV. Madrid, Instituto Jerónimo Zurita, 1973, p. 289-380.

URQUIJO GOITIA, J. R., Los servicios de información en la Primera Guerra Carlista. Publicado en el volumen Los servicios de información modernos y contemporáneos de la Revista de Historia Militar. Ed. Instituto de Historia y Cultura Militar, año XLIX (2005)

VARELA SUANZES-CARPEGNA, J., "La construcción del Estado en la España del siglo XIX. Una perspectiva constitucional'. Bulletin d' Histoire Contemporaine de l' Espagne. Des Lumières au libéralisme, núm. 37-47 (juin 2004-décembre 2006). 